\title{
Associations between second-hand smoke exposure in pregnancy and age of childhood asthma development
}

\author{
Elinor Simons ${ }^{1,2^{*}}$, Teresa To ${ }^{1}$, Rahim Moineddin ${ }^{3}$, David Stieb ${ }^{4}$, Sharon Dell ${ }^{1,2}$ \\ From Canadian Society of Allergy and Clinical Immunology Annual Scientific Meeting 2012 \\ Calgary, Canada. 11-14 October 2012
}

\section{Background}

Maternal smoking during pregnancy has been associated with an increased hazard of incident childhood asthma. We investigated the association between any secondhand smoke exposure in early life and childhood asthma development.

\section{Methods}

In the Toronto Child Health Evaluation Questionnaire, parents of 5619 grades 1-2 students reported age of physician-diagnosed asthma development, exposure to maternal and household second-hand smoke during pregnancy and the first year of life, socio-demographic factors, and other early-life exposures such as mold and cockroach. Using Cox proportional hazard models, we evaluated the longitudinal associations between second-hand smoke exposure and age of asthma development.

\section{Results}

Household second-hand smoke exposure prevalence was $8.3 \%$ during pregnancy and $10.6 \%$ in the first year of life; $15.5 \%$ of children developed asthma. After adjusting for sex, prematurity, being born in Canada and maternal asthma, children exposed to home second-hand smoke during pregnancy were more likely to develop asthma and developed asthma sooner [adjusted hazard ratio (HR) 1.36, 95\% confidence interval (CI): 1.09, 1.70], even after excluding children whose mothers smoked in pregnancy (HR 1.53, 95\% CI: 1.09, 2.14). The association strengthened (HR 1.88, 95\% CI: 1.16, 3.02) after adjusting for home second-hand smoke exposure in the first year.

\footnotetext{
* Correspondence: elinor.simons@sickkids.ca

${ }^{1}$ The Hospital for Sick Children, Child Health Evaluative Sciences, Toronto, ON, Canada

Full list of author information is available at the end of the article
}

\section{Conclusions}

Home second-hand smoke exposure during pregnancy is associated with an increased hazard of childhood asthma development, even if the mother is not a smoker. Recommendations for smoking cessation during pregnancy should focus on pregnant women and members of their households.

\section{Author details}

${ }^{1}$ The Hospital for Sick Children, Child Health Evaluative Sciences, Toronto, ON, Canada. ${ }^{2}$ The Hospital for Sick Children, Division of Respiratory Medicine, Toronto, ON, Canada. ${ }^{3}$ The University of Toronto, Department of Family and Community Medicine, Toronto, ON, Canada. ${ }^{4}$ Health Canada, Ottawa, ON, Canada.

Published: 2 November 2012

doi:10.1186/1710-1492-8-S1-A4

Cite this article as: Simons et al:: Associations between second-hand smoke exposure in pregnancy and age of childhood asthma development. Allergy, Asthma \& Clinical Immunology 2012 8(Suppl 1):A4.

Submit your next manuscript to BioMed Central and take full advantage of:

- Convenient online submission

- Thorough peer review

- No space constraints or color figure charges

- Immediate publication on acceptance

- Inclusion in PubMed, CAS, Scopus and Google Scholar

- Research which is freely available for redistribution

Submit your manuscript at www.biomedcentral.com/submit
() Biomed Central

\section{() Biomed Central}

